\title{
Facilitation displaces hotspots of diversity and allows communities to persist in heavily stressed and disturbed environments
}

Yoann Le Bagousse-Pinguet, Sa Xiao, Rob W. Brooker, Nicolas Gross, Pierre Liancourt, Dietmar Straile \& Richard Michalet

\section{Keywords}

Community theory; C S R triangle; Environmental gradients; Expansion and extinction of communities; Facilitation; Hotspots of diversity; Simulation; Species distributions

\begin{abstract}
Question: What are the interacting effects of stress and disturbance on both competition and facilitation, and ultimately their impact on diversity and species ranges?
\end{abstract}

Location: Simulated data.

Method: We extended the spatially explicit model of Xiao et al. (Oikos, 118, 2009,1343 ) to consider how stress and disturbance operating alone or together affect species distributions through varying biotic interactions.

Results: In the absence of facilitation, species ranges only occurred within the limits of a triangular zone, which can be considered equivalent to Grime's C S R triangle. Competitive species were distributed in low stress and disturbance con ditions. Stress and disturbance tolerant species occurred in more stressed and disturbed environments. Species richness followed a hump shaped relationship with a hotspot of diversity occurring close to the centre of the C S R triangle. In contrast, facilitation was able to dampen the negative impacts of stress and dis turbance acting either solely or simultaneously, but this influence was not sim ply the sum of the effects of the processes operating independently on the two environmental gradients. Facilitation extended species distributions along both the stress and disturbance gradients and displaced the hotspot of diversity into the centre of the response surface.

Conclusions: Facilitation was able to promote the occurrence and persistence of communities in highly stressed and disturbed conditions, i.e. allowing a stable community to exist beyond the limits of the C S R triangle. We also showed that facilitation can be an important mechanism driving the displacement of hotspots of diversity from benign toward intermediate stressed and disturbed environ ments. 


\section{Introduction}

Facilitation can affect species richness of plant communi ties (Hacker \& Gaines 1997; Bruno et al. 2003; Michalet et al. 2006; Brooker et al. 2008) by alleviating the impacts of stress (i.e. factors limiting plant development such as water or nutrient limitation, sensu Grime 1973, 1974) or disturbance (drastic events removing plant bio mass such as mowing or grazing) on species that would otherwise be intolerant to the local conditions (Hacker $\mathcal{G}$ Gaines 1997). This enlargement of species realized niches (Bruno et al. 2003) enables increased species ranges and thus at some points along environmental gradients enhanced community richness, effectively 'pulling in' species that would otherwise be intolerant of the prevail ing environmental conditions (Hacker \& Gaines 1997; Bruno et al. 2003; Liancourt et al. 2005; Michalet et al. 2006; Gross et al. 2010). However, recent studies have also shown that facilitation may in some circumstances reduce diversity by promoting the survival of competitive species (Gross et al. 2009; Xiao et al. 2009). In addition, as the effect of facilitation is not constant along environ mental severity gradients (Bertness \& Callaway 1994; Brooker \& Callaghan 1998; Homgren \& Scheffer 2010; Malkinson \& Tielbörger 2010), its influence on species ranges and hence richness is likely to strongly depend on prevailing environmental conditions (Michalet et al. 2006; Brooker et al. 2008).

Facilitation is acknowledged to play a stronger role in regulating plant community composition in more stressed and disturbed conditions than in benign environments (Bertness \& Callaway 1994; Hacker \& Gaines 1997). A number of studies have also reported that facilitation can either wane or switch to competition at very high levels of stress (e.g. Maestre \& Cortina 2004; Maestre et al. 2005; Anthelme et al. 2007) or disturbance (Brooker et al. 2006; Smit et al. 2007; Le Bagousse Pinguet et al. 2012a). Thus, facilitation is likely to be important for regulating diversity in plant communities subjected to intermediate to high levels of stress or disturbance (Hacker \& Gaines 1997; Michalet et al. 2006).

However, although some studies have focused on stress or disturbance gradients independently (Grime 1973; Hacker \& Gaines 1997; Bruno et al. 2003; Michalet et al. 2006; Xiao et al. 2009), or have considered them to be negatively correlated (Bertness \& Callaway 1994), envi ronmental severity gradients are often complex in nature, including direct factors which, although potentially inter acting to regulate outcomes at the community level, fluc tuate independently. For example, disturbance processes can occur along the full length of a stress gradient, with their severity being independent of the level of stress (e.g. Eskelinen 2008; Veblen 2008; Anthelme \& Michalet
2009). Modelling studies have addressed the impact of biotic interactions such as competition (Huston 1979) and predation (Menge \& Sutherland 1987) on diversity when both stress and disturbance interact (along a productivity gradient). At the same time, there have been a number of studies attempting to understand the interactive effects of variation in stress and disturbance on both facilitation and competition, but these works have not considered the con sequences for diversity (e.g. Smit et al. 2007; Le Roux $\delta$ McGeoch 2010; Bullieri et al. 2011; but see Maalouf et al. 2012). Therefore, our understanding of the effect of biotic interactions (both competition and facilitation) on com munity composition and diversity remains unclear. This lack of clarity is not just of theoretical interest. Understand ing how and where biotic interactions including facilita tion play a critical role in regulating species ranges, and thus community richness, is crucial for conservation (Brooker et al. 2008).

In this study, we apply an individual based spatially explicit model to explore the impact of stress and distur bance (operating independently but potentially inter acting within the model space) on plant interactions, and ultimately on species diversity and ranges. Such models have been successfully used to study the inter play of facilitative and competitive interactions along single 'severity' gradients (Travis et al. 2005, 2006; Xiao et al. 2009), to evaluate the effects of both biotic inter actions and environmental change on species distribu tions (Brooker et al. 2007), the effects of species pool, dispersal and competition on the diversity productivity relationship (Xiao et al. 2010), and to test the evolu tionary consequences of facilitative interactions on spe cies composition (Michalet et al. 2011; Liancourt et al. 2012). But they have not been used previously to address the challenge tackled here, specifically to exam ine how stress and disturbance operating alone or together affect species diversity and distributions through the regulation of biotic interactions. In particu lar, we aim to test whether these regulating factors, although operating independently, might have either additive (Zavaleta et al. 2003) or non additive effects on species diversity and distributional ranges (Brooker et al. 2008), and whether potential non additive effects can be mediated by biotic interactions. We do not have any a priori hypothesis regarding the potential interac tive effects of stress and disturbance. However, we expect that (1) facilitation will promote species richness by dampening the negative effects of stress and distur bance either operating alone or together (Hacker $\delta$ Gaines 1997; Michalet et al. 2006), and that (2) facilita tion will also enlarge species ranges, particularly in highly stressed and disturbed environments (Hacker $\delta$ Gaines 1997; Bruno et al. 2003). 
We frame our study within the concepts of one of the key models of plant community ecology, Grime's (1974) C S R strategy theory: we consider how the effects of plant interactions alter the composition of communities in terms of the representation of different plant strategies. Our study explores how plant interactions modulate species diversity and ranges (outcome of the model) with respect specifically to Grime's (1974) C S R triangular ordination.

\section{Model description}

Simulations were performed in NetLogo (Northwestern University, Evanston, IL, US; Chu et al. 2008), a powerful multi agent modelling language particularly well suited for modelling complex systems developing over time. The model description generally follows the overview, design concepts and details (ODD) protocol for individual based models (Grimm et al. 2006). We used in this study a very similar model to those exploring the interplay of competi tion and facilitation along environmental severity gradi ents (Xiao et al. 2009), the role of biotic interactions and dispersal on the diversity productivity relationship (Xiao et al. 2010) and the evolutionary consequences of facilita tion on species composition (Michalet et al. 2011). Specifi cally, we aimed in this study to disentangle the 'environmental severity gradient' used in the spatially explicit simulation model of Xiao et al. (2009) into stress and disturbance.

The lattice has a size of $500 \times 500$ cells. Within the lat tice we located 100 square 'sampling plots', each of $50 \times 50$ cells. It is important to note that the lattice, by incorporating independently functioning axes of stress and disturbance, represents Grime's (1974) C S R triangle. We necessarily extended it to incorporate areas with high lev els of stress and disturbance that lie outside of the cover age of the original triangle to test whether facilitation can enable species to persist in these conditions.

All the simulations were run for 50000 time steps in order to allow the community to reach a steady state (Appendix S1). Species richness was determined for every plot independently as the mean value during the 1000 time steps immediately after the 50000 start up steps (i.e. once the community has achieved its steady state). We took a 'wraparound' (torus) approach to avoid edge effects (Yamamura et al. 2004; Xiao et al. 2009, 2010; Michalet et al. 2011). All simulations were started with saturated communities having the same species number as the regio nal species pool ( $R \quad 200$, see below). Each species within the community is represented by 1250 (250 000/200) individuals, and all individuals are randomly dispersed within the lattice. The parameters used in the simulations

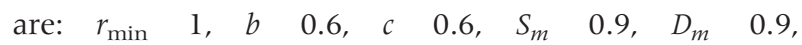
I 0.005 (see below for descriptions of parameters). The robustness of the model was tested with different combina tions of parameters; the results were qualitatively the same as with the combination reported here (see also Xiao et al. 2009, 2010; Michalet et al. 2011).

In the model, all species co exist within the local com munity. Each cell of the lattice can be empty or occupied by one individual, irrespective of species. The neighbour hood is defined as the Moore neighbourhood (Ifti et al. 2004), and consists of the eight immediate neighbours of a given cell: north, northeast, east, southeast, south, southwest, west and northwest. Stress increases linearly from the left to the right end of the lattice. The variable $S$ represents the degree of stress $(0 \leq S \leq 1)$. $S \quad 0$ indi cates the most benign environment, and $S \quad 1$ the hars hest environment. Disturbance increases linearly from the bottom to the top of the lattice. The variable $D$ represents the degree of disturbance $(0 \leq D \leq 1)$. $D \quad 0$ indicates the most stable environment and $D \quad 1$ the most dis turbed environment. Consequently, the lattice contains the suite of all possible combinations of both stress and disturbance.

According to Grime's C S R model $(1973,1974)$ there are trade offs between species competitive ability, stress tolerance and reproductive ability, resulting in the occur rence of three plant strategies, i.e. competitive (C), stress tolerant (S) and ruderal (R) species. We define $a_{C i}, a_{S i}$ and $a_{R i}$, respectively, as the competitive ability, stress tolerance and reproductive ability of species $i$. Consistent with the theory of trade off, $a_{C i}+a_{S i}+a_{R i} \quad$ l.

Although potentially influenced by stress and distur bance (and their subsequent regulation of interactions) in natural communities, for simplicity we consider both establishment and reproduction within our model to oper ate independently of $S$ and $D$. Competitive ability $a_{C i}$ is characterized as the ability of species $i$ to exclude other spe cies. When a propagule of species $i$ is dispersed to a cell occupied by another species $j$, the probability for species $i$ to exclude species $j$ and to invade the cell is equal to $a_{C i} \quad a_{C j}$. The probability is equal to zero when $a_{C j}>a_{C i}$, thus only species with a stronger competitive ability can invade cells that are already occupied.

The reproductive rate $a_{R i}$ of species $i(r)$ is defined as:

$$
r_{i}=r_{\min } /\left(\begin{array}{ll}
1 & c a_{R i}
\end{array}\right)
$$

where $c$ is a constant that is positive and smaller than 1 , and $r_{\min }$ is the minimum value of a species reproductive rate, which is always smaller than 1 . Therefore the repro ductive rate of species will increase with increasing $a_{R i}$ values.

Within the model, stress and disturbance ( $S$ and $D$, respectively) directly impact on adult survival and mortal ity. The species stress tolerance $a_{S i}$ is defined as the ability 
of species $i$ to survive under a given level of stress. Thus the survival rate of species $i\left(s u_{i}\right)$ is defined as:

$$
\mathrm{su}_{i}=1 \quad\left(\begin{array}{ll}
1 & b a_{S i}
\end{array}\right) S
$$

where $b$ is a constant that is positive and smaller than 1 , and $s u_{i}$ is positive and smaller than 1 . The survival rate of a species with high $a_{S i}$ will decrease more slowly with increasing stress than will that of a species with a low $a_{S i}$. Note that the presence of neighbours does not increase the level of stress experienced by an individual as might occur in the case of resource competition; competition within the model is for establishment space only.

According to the stress gradient hypothesis (Bertness $\delta$ Callaway 1994; Brooker \& Callaghan 1998), facilitation received by beneficiary species increases with increasing stress. In the model, facilitation increases species survival rates along the stress gradient. However, facilitation also wanes in the most severe conditions (Michalet et al. 2006), from a threshold stress level $\left(S_{m}\right)$ to be equal to zero when $S \quad 1$ (Fig. 1a; see Xiao et al. 2009). Therefore, when facilitation is included in our model, the survival rate of species $i$ along the stress gradient is defined as:

$$
\begin{aligned}
& \mathrm{su}_{i}=1 \quad\left(\begin{array}{ll}
1 & b a_{s i}
\end{array}\right) S+f_{s} S \text { when } S<S_{m} \\
& \mathrm{su}_{i}=1 \underset{\text { when } S>S_{m}}{\left(\begin{array}{lll}
1 & b a_{s i}
\end{array}\right) S+f_{S}\left(\begin{array}{lll}
1 & S
\end{array}\right) S_{m} /\left(\begin{array}{lll}
1 & S_{m}
\end{array}\right)}
\end{aligned}
$$

where $f_{s}$ is a constant, which is larger than zero, and indi cates the intensity of the positive effect received by a tar
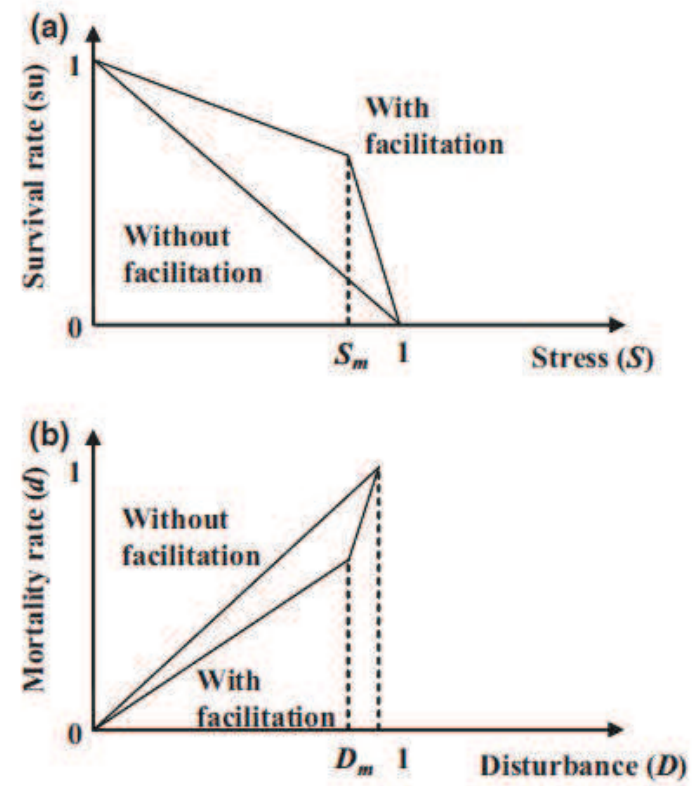

Fig. 1. Representation of (a) Survival rate (su) and (b) mortality rate (d) of species with and without facilitation as a function of stress (5) and disturbance level $(D)$. get species $i$ from its neighbours along the stress gradient. When $f_{s} \quad 0$, there is no facilitation. According to simula tion results of Xiao et al. (2009), a value of $f_{s} \quad 0.5$ indi cates intense facilitation. To better illustrate the impact of facilitation on the survival rate of species $i$ along the stress gradient, we used arbitrarily different intensities of facilita tion as following: no facilitation $\left(f_{s} \quad 0\right)$, low facilitation $\left(f_{s} \quad 0.1\right)$, medium facilitation $\left(f_{s} \quad 0.3\right)$ and intense facili tation $\left(f_{s} \quad 0.5\right)$.

In our model, facilitation reduces disturbance induced mortality. Species mortality rate due to disturbance $(d)$ increases with increasing disturbance $(D)$. Facilitation received by beneficiary species also increases with increas ing disturbance (Bertness \& Callaway 1994; Hacker \& Gaines 1997; Brooker \& Callaghan 1998). Facilitation also wanes in highly disturbed conditions because beneficiary species cannot induce any facilitative effect (Brooker et al. 2006; Le Bagousse Pinguet et al. 2012a). For example, increased herbivore search effort induces a decrease in a benefactor's protection in very heavily browsed systems (Brooker et al. 2006; Smit et al. 2007). Disturbance facili tation declines in the model from a threshold disturbance level $\left(D_{m}\right)$ to be equal to zero when $D \quad 1$ (Fig. 1b; Xiao et al. 2009). Therefore, when facilitation is included in our model, the mortality rate of species $i$ along the disturbance gradient can be defined as:

$$
d_{i}=\left(\begin{array}{ll}
1 & f_{D}
\end{array}\right) D, \quad \text { when } D<D_{m}
$$

$\left.d_{i}=\left(\left(\begin{array}{lll}1 & (1 & f_{D}\end{array}\right) D_{m}\right) D \quad f_{D} D_{m}\right) /\left(\begin{array}{ll}1 & D_{m}\end{array}\right)$ when $D>D_{m}$

where $f_{D}$ is a constant that is larger than zero and indi cates the intensity of the positive effect received by a target species $i$ from its neighbours along the distur bance gradient. When $f_{D} \quad 0$, there is no facilitation. In contrast, a value of $f_{D} \quad 0.5$ indicates intense facilitation (Xiao et al. 2009). To better illustrate the impact of facilitation on the mortality rate of species $i$ along the disturbance gradient, we used the following intensities of facilitation: no facilitation $\left(f_{D} \quad 0\right)$, low facilitation $\left(f_{D} \quad 0.1\right)$, medium facilitation $\left(f_{D} \quad 0.3\right)$ and intense facilitation $\left(\begin{array}{ll}f_{D} & 0.5\end{array}\right)$.

We consider in the model only inter specific facilitation, which occurs when other species are present in the target species neighbourhood (Xiao et al. 2009), and we assume for simplicity that values of both $f s$ and $f_{D}$ are the same for all species. Variation of $s u_{i}$ along the stress gradient and variation of $d_{i}$ along the disturbance gradient, both with and without facilitation, are shown in Fig. la,b, respec tively.

During each model time step, each individual within the community experiences first the possibility of mortality due to disturbance (with a mortality probability $d_{j}$, 
i.e. independent of its strategy) and second the possibility of mortality due to stress (with a survival probability $s u_{i}$, which is influenced by the stress tolerance of the species). Only the final survivors are able to reproduce and to dis perse their propagules. From an organismal point of view, disturbance constitutes a drastic event in the model affect ing all individuals (and independent of their strategies), and species persistence is due only to the species ability to re colonize. In contrast, stress differs from disturbance by not impacting all plant strategies in a similar way. Stress only affects the survival of non adapted species (i.e. the relatively more competitive or ruderal species, and hence less stress tolerant species).

When reproduction occurs, an individual produces propagules that are identical to the parents (Xiao et al. 2009; Michalet et al. 2011). The total number of propa gules produced by an individual of species $i$ equals the spe cies reproductive rate $r_{i}$, and each propagule is dispersed to one of the cells within the parent's neighbourhood (eight cells surrounding the parents). The decimal portion of $r_{i}$ is compared to $Q$, a uniform random number on the $\{0,1\}$ interval. If $r_{i}$ is larger than $Q$, the total number of propa gules equals the integer portion of $r_{i}$ plus 1 ; otherwise, it equals the integer portion of $r_{i}$. The propagules of any spe cies can invade empty cells.

We incorporated immigrations of species from the regio nal species pool to the local community (the lattice). The total number of species in the regional species pool is $R$. The $a_{C i}$ values of each species are randomly drawn between 0 and 1 , then $a_{S i}$ values of each species are ran domly drawn between 0 and $1 \quad a_{C i}$, and $a_{R i}$ is

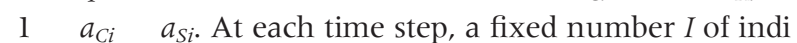
viduals are randomly drawn from the regional species pool to the local community such that each individual has a probability of $1 / R$ to belong to each of the $R$ species (Xiao et al. 2009; Michalet et al. 2011). Therefore, $I$ indicates the immigration rate of species from the regional species pool to the local community. Immigrating individuals are ran domly dispersed across the landscape of the local commu nity (the lattice).

\section{Testing the relationship between disturbance, stress and facilitation}

We examined whether stress and disturbance acting together had interactive (synergistic or antagonistic) effects, and whether any such interactions between the two gradients were modified by the occurrence of facilita tion. We used community distribution range $(D R)$ as a metric for comparison. The community distribution range $(D R)$ corresponds to the mean values of community range distributions (the number of grid cells occupied by individuals across the whole lattice) calculated from the
1000 time steps after the run of 50000 start up steps, i.e. when the community was stabilized. We used the relative interaction index (RII; Armas et al. 2004) to examine the response of $D R$ to the occurrence of either $S$ or $D$ alone or together. We then also compared these differences when facilitation was absent or operating in the model. RII values were calculated using mean values of $D R$ captured at the 1000th time step in each of 1000 replicates for each set of model parameters.

Comparisons were calculated as:

$$
\begin{aligned}
& R I I_{D}=\left(D R_{\text {without Disturbance without Stress }}\right. \\
& \left.D R_{\text {with Disturbance without Stress }}\right) \times(\text { higher value })^{-1} \\
& R I I_{D S}=\left(D R_{\text {without Disturbance with Stress }}\right. \\
& \left.D R_{\text {with Disturbance with Stress }}\right) \times(\text { higher value })^{-1} \\
& R I I_{S}=\left(D R_{\text {without Stress without Disturbance }}\right. \\
& \left.D R_{\text {with Stress without Disturbance }}\right) \times(\text { higher value })^{-1} \\
& R I I_{S D}=\left(D R_{\text {without Stress with Disturbance }}\right. \\
& \left.D R_{\text {with Stress with Disturbance }}\right) \times(\text { higher value })^{-1}
\end{aligned}
$$

Potential interacting effects of disturbance and stress can be assessed by comparing values of $R I_{D S}$ and $R I_{D}$, and between $R I I_{S}$ with $D$ and $R I I_{S}$ without $D$.

If $R I I_{D S} R I I_{D}$ or $R I I_{S D} R I I_{S}$, no interactive effect between stress and disturbance occurs (additive effects).

If $R I I_{D S}>R I I_{D}$ or $R I I_{S D}>R I I_{S}$, the presence of either stress or disturbance increases the impact of the other fac tor on the community range distribution, i.e. it indicates the occurrence of a synergistic effect.

If $R I I_{D S}<R I I_{D}$ or $R I I_{S D}<R I I_{S}$, the presence of either stress or disturbance decreases the impact of the other fac tor on the community range distribution, i.e. it indicates the occurrence of an antagonistic effect.

\section{Results and discussion}

In the absence of facilitation, species only occurred within the limits of a triangular zone that can be considered equivalent to Grime's (1974) C S R triangle (Fig. 2a; asso ciated species richness is shown in Fig. 3 as the blue response surface). Competitive species were distributed in low stress and disturbance conditions. Stress and distur bance tolerant species occurred in more stressed and dis turbed environments, respectively (Fig. 2a). Hotspots of diversity occurred close to the centre of the C S R triangle (Fig. 2a black circle; Fig. 3 maximum of the blue response surfaces). Species richness is low under very low stress and disturbance levels due to strong competitive exclusion, and under high stress and/or disturbance due to the intol 

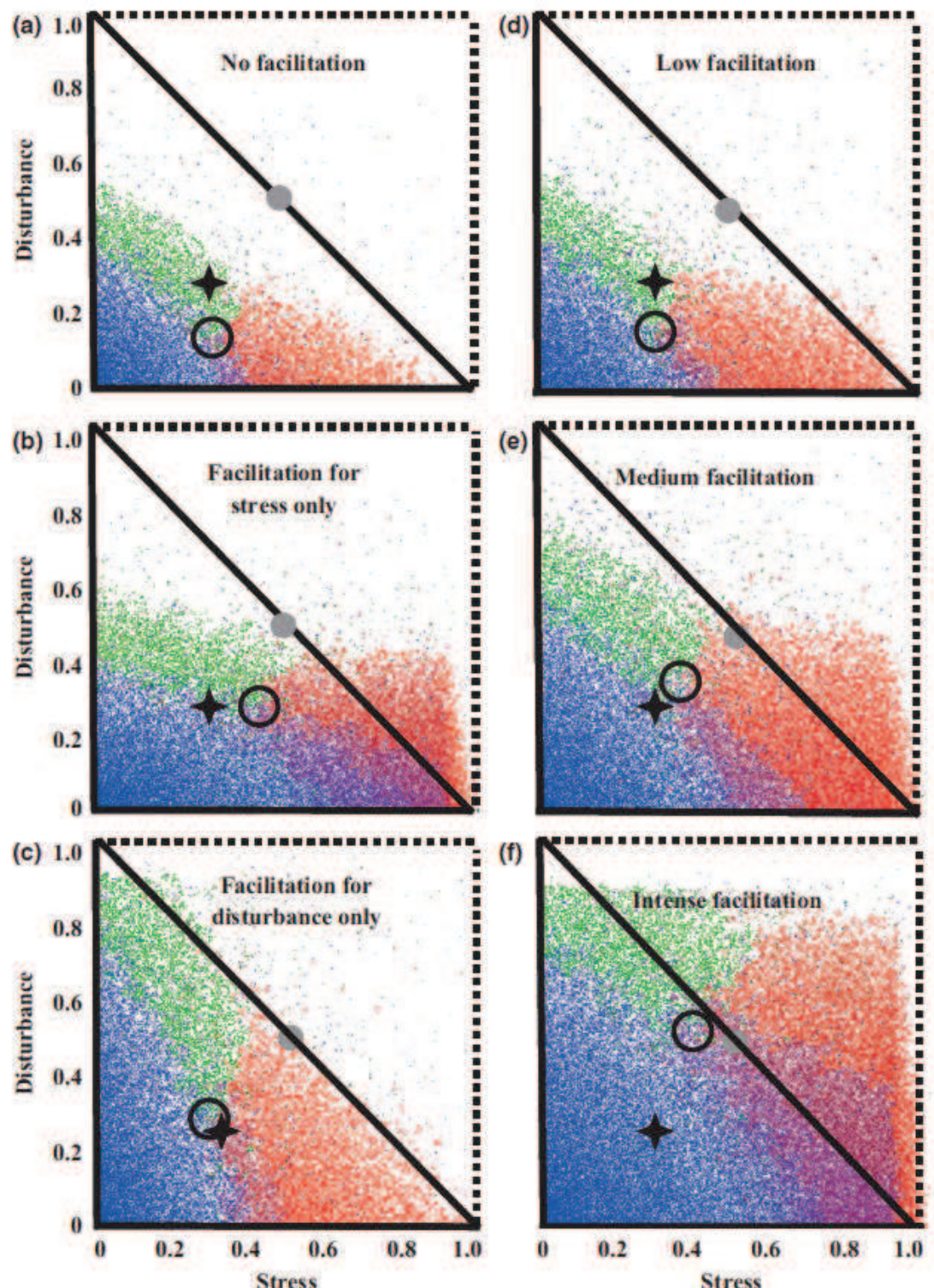

Fig. 2. The spatial distributions of competifive (blue dots), stress toler ant (red) and disturbance tolerant (green) species along gradients of stress $(S)$ and disturbance (D). Colours of species strategies are defined by the RGB colour system with its value equal to $\left(50 \times a_{s}, 50 \times a_{R}, 50 \times a_{d}\right)$. Resultant species distributional ranges are presented (a) in the absence of facilitation (fs $0, f_{D} \quad 0$ ), (b) with facilitation occurning along the stress gradient only (fs 0.5 , $f_{D} \quad 0$ ), (c) with faciltation occurring along the disturbance gradient only (fs $0, f_{D} \quad 0.5$ ), (d) with low facilitation along both gradients ( $\left.f_{5} \quad 0.1, f_{D} \quad 0.1\right)$, (e) with medium facilitation ( $f S \quad 0.3, f_{D} \quad 0.3$ ), and ( $f$ ) with intense facilitation ( $f s \quad 0.5, f_{D} \quad 0.5$ ). Note that the black triangles represent the location and black stars the centre of the CS R triangle (Grime 1974), i.e. the prediction where the diversity may range. Grey dots indicate the centre of our model space and black cirdes represent hotspots of diversity.

erance of most species to the severe environmental condi tions. In this sense, the results of our model match the expectations of theory (e.g. Grime 1973, 1974; Huston 1994).

The expectations of theory concerning the hump shaped variation of diversity along environmental gradi ents have been recently discussed (Adler et al. 2011; Frid ley et al. 2012). Adler et al. (2011) found no clear relationship between productivity and species richness (but see Fridley et al. 2012) and encouraged the use of modelling approaches to consider multiple interacting fac tors on species diversity. By testing how stress and disturbance, operating alone or together, affect species diversity, our results confirm the occurrence of a hump shaped pattern of diversity.

An interesting output from the model is that disturbance appears to have a stronger effect on communities than stress (Fig. 4a,b). Thus, the collapse of diversity is more 

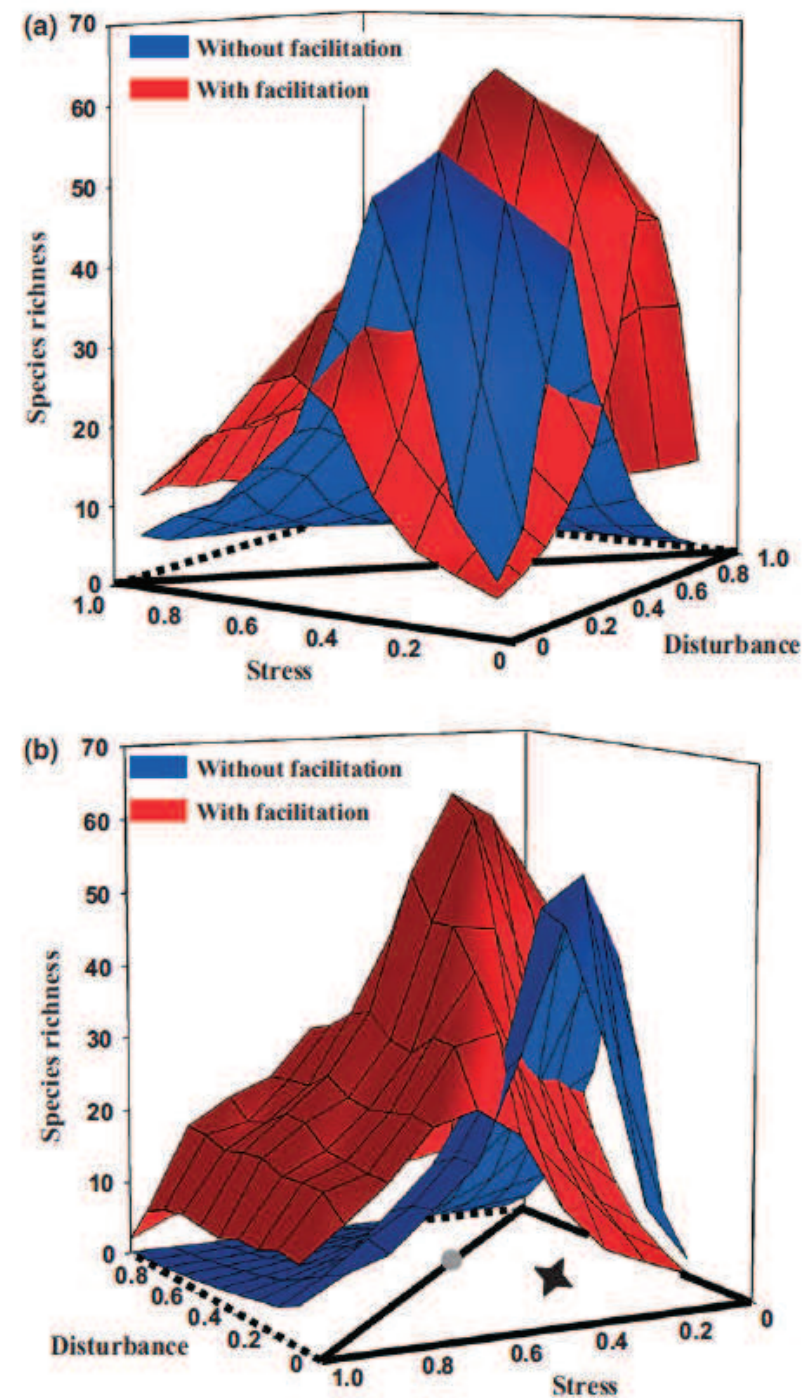

Fig. 3. Response surface of variation in species richness in relation to changes in stress $(S)$ and disturbance $(D)$ with intense facilitation (red surface) and without facilitation (blue surface). The same response surface is presented from two different points of view ( $\mathbf{a}$ and $\mathbf{b}$ ) to better illustrate its three dimensional shape. Black triangles represent the location and black stars the centre of the CSR triangle (Grime 1974), while grey dots indicate the centre of our response surface model.

severe along the disturbance gradient than along the severity gradient (Fig. 2a). This might be because in our model the impacts of disturbance and stress are modelled in different ways. Disturbance is an event equally affecting all individuals and affecting both survival and reproduc tion (Hastwell \& Facelli 2003), whereas stress is a phenom enon acting in our model only on survival (Xiao et al. 2009). Hence, for any given level of these factors, the impact is actually higher for disturbance. Consequently, the collapse of diversity occurs at a lower threshold along the disturbance gradient than along the stress gradient

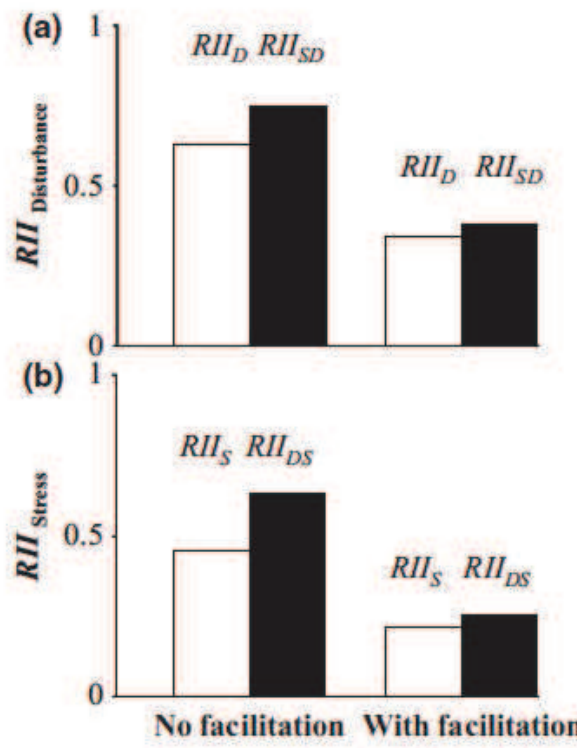

Fig. 4. Relative interaction index (RII) calculated for the impacts on the mean community distribution range (DR) of (a) disturbance and (b) stress operating either independently (white bars) or in the presence of the other factor (black bars). The response of RII values to the independent or simultaneous action of stress and disturbance gradients on DR are also shown in the absence and presence of facilitation. Note that all RII values were positive, indicating consistently negative effects on species distributions.

(Fig. 2b,c). Drastic events affecting all species strategies (e.g. overgrazing, fire or mowing) may have a stronger impact on natural plant communities than environmental drivers related to species tolerances (e.g. water stress). Note also that we did not include in our model selective distur bance events (e.g. grazing) that would have affected the outcome of the model. However, as species with particular adaptations might tolerate or avoid disturbances, selective disturbances might have less severe effects on the distribu tions.

The simulation run indicated that as shown by previ ous modelling and field studies facilitation extends spe cies distributions, and hence the zones that can be occupied by communities, along both the stress and dis turbance gradients (Fig. 2b,c). When facilitation occurred along only a single gradient (e.g. on the stress but not the disturbance gradient), unsurprisingly it was along that gradient alone that the increased distribution of spe cies and communities occurred. Facilitation has been shown to promote the persistence of intolerant species by alleviating stress (e.g. Hacker \& Gaines 1997) or by pro tecting against disturbance (e.g. Hacker \& Gaines 1997; Le Bagousse Pinguet et al. 2012a), and therefore to enlarge species ecological niches (Bruno et al. 2003; Gross et al. 2010) and consequently ranges, and thus our model is recreating the patterns found in natural systems. 
Importantly, however, our study has extended previous modelling work by incorporating multiple species with a range of strategies based upon the C S R strategy trade off model. Our model shows that facilitation promotes the survival of relatively less stress /disturbance tolerant species for any given level of $S$ or $D$ (Fig. 2b,c), and thus supports previous theoretical and field studies that have proposed and detected such a process (e.g. Liancourt et al. 2005; Michalet et al. 2006).

We found synergistic effects of the two gradients: the impact of disturbance in the presence of stress $\left(R I_{D S}\right)$ was proportionately higher than disturbance alone $\left(R I I_{D}\right)$, and the same held true for the impact of stress in the presence and absence of disturbance, i.e. $R I_{S D}$ was greater than $R I_{S}$ (Fig. 4). Interestingly, our results also showed that facilita tion reduced the negative impacts of stress and disturbance occurring either alone or simultaneously: overall RII val ues were lower in the presence of facilitation, and there was a proportionately smaller synergistic effect (Fig. 4).

The effect of facilitation on individual species translated at the community level into the displacement of the hot spot (peak) of diversity into the centre of our response sur face (Fig. 2d f: black circles, Fig. 3a,b: red response surfaces), and toward the lower edge (the S R line) of the C S R triangle. To date, no empirical data are available to validate our model predictions. Only a few recent 'real world' studies have documented variation in biotic interac tions when both stress and disturbance co occur, but these have not considered their impact on diversity (Eskelinen 2008; Veblen 2008; Anthelme \& Michalet 2009; Le Roux \& McGeoch 2010; Bullieri et al. 2011). However, our results are in accordance with Grime's (1974) empirical data from the UK on the characterization of diversity along stress and disturbance gradients, in which maximum diversity occurs midway along the S R axis (see Fig. 4 in Grime 1974). In Grime's work, this location in the triangle corresponds to the mesophilous Bromus erectus communities (Grime 1974; Al Mufti et al. 1977), where moderate drought, nutrient deficiency and disturbance are associated with high levels of species richness (Dutoit \& Alard 1995; Michalet et al. 2002). In these previous studies competition was the only type of interaction thought to be involved. However, our simulations clearly indicate that it may also be induced in part by facilitation (including the dampening of synergistic effects between the two types of severity). In support of this interpretation, Liancourt et al. (2005) showed that, under a range of contrasting environmental conditions studied in a similar system in the French Alps, facilitation was strongest under this combination of environmental drivers.

One of the most interesting results of our model con cerns the highly stressed and disturbed corner of our land scape (Fig. 2). At this location, in the absence of facilitation, species richness is zero (Fig. 2a), supporting the prediction that no species strategies are able to tolerate such high levels of both constraints (Grime 1974). How ever, increased facilitation enlarged species ranges into highly stressed and disturbed conditions (Fig. 2 d f) and allowed a stable community to exist beyond the limits of the C S R triangle, i.e. beyond the limits of individual spe cies tolerances. As such, facilitation not only promoted the persistence of species that would otherwise be intolerant to these conditions, it also promoted the success of dominant (i.e. stress or disturbance tolerant) species (Gross et al. 2009).

This result highlights the potential role of facilitation in enabling the occurrence and maintenance of communi ties in highly stressed and disturbed environments, as reported in terrestrial (Holmgren et al. 2001; Kéfi et al. 2007; Malkinson \& Tielbörger 2010) and aquatic (Schef fer $\&$ Carpenter 2003; Le Bagousse Pinguet et al. 2012b) ecosystems. Kéfi et al. (2007) showed, through a combi nation of field surveying and modelling, that positive interactions could explain the spatial organization of veg etation in three arid Mediterranean ecosystems character ized by high stress (water stress) and disturbance (grazing). However, with increasing disturbance, facilita tion could not prevent the decline of vegetation and onset of desertification. Thus, the simultaneous effects of both stress and disturbance may lead to a rapid extinction of plant communities (Holmgren et al. 2001; Kéfi et al. 2007).

Overall, although an inherent assumption of the model consisted of a dampening effect of facilitation on stress and disturbance separately, our results illustrate that facilita tion can also limit their synergistic effects, and promote increased species richness. However, these effects of facili tation on diversity are context dependent, i.e. the effect of facilitation on species diversity changes along disturbance and stress gradients. Consistent with Gross et al. (2009) and Xiao et al. (2009), facilitation decreased species rich ness in the benign conditions of our model (low stress and disturbance) by promoting dominant competitive species (Fig. 3a,b: red curves) leading to long term competitive exclusion (Xiao et al. 2009). Conversely, and in concor dance with several theoretical models (Hacker \& Gaines 1997; Bruno et al. 2003; Michalet et al. 2006; Brooker et al. 2008), facilitation promoted species richness under increased environmental severity (high stress and/or dis turbance).

\section{Conclusions}

Utilizing concepts from Grime's C S R plant strategy the ory, our model has extended previous work of this kind by using a multi species system to demonstrate the 
movement of the zone of highest species richness (as well as simply species ranges) due to facilitation, as well as the potential for communities to occur in highly stressed and disturbed environments, i.e. in environments previously thought to not support any plant strategies.

In addition, our model has suggested synergistic interac tions of the stress and disturbance gradients, and the capacity for facilitation to dampen this synergistic effect. The synergism in the current model is the result of emer gent model processes, i.e. we have not specifically pro grammed an interaction between these two gradient types. However, alternative scenarios of interactions between stress and disturbance might occur. For instance, distur bance might reduce the stress level by increasing the resource availability (e.g. by limiting resource competition) and countering negative effects imposed by stress on spe cies distributions. Future modelling could extend the work conducted here by incorporating such direct mechanisms for the interaction of the two types of gradient. Irrespec tive, the results presented here represent the first attempt to model the interaction of stress and disturbance gradi ents, the response of species richness and the impacts of facilitation.

Examining the role of facilitation in regulating species richness and distributions along gradients, considered solely or simultaneously, is important not only for our basic understanding of the functioning of natural sys tems, but also for the management and conservation of ecosystems. For example, the combination of stress and disturbance can modify transitions from one stable state to another, and studying their simultaneous effects is relevant to impeding the extinctions of communities both in terrestrial (e.g. Holmgren et al. 2001; Kéfi et al. 2007) and aquatic (Scheffer \& Carpenter 2003; Le Bago usse Pinguet et al. 2012b) ecosystems. We particularly advocate further modelling approaches manipulating dif ferent scenarios of interactions between stress and dis turbance to test their effects on variations in biotic interactions and, ultimately, on species richness and dis tribution.

\section{Acknowledgements}

This research project was part of the Collaborative Research Center (CRC) no. 454 "Littoral of Lake Con stance". Y.L.B.P. was financially supported by the Deut sche Forschungsgemeinschaft (DFG), the French ANR 09

STRA 09 O2LA and by the project Postdoc USB (reg. no. CZ.1.07/2.3.00/30.0006) realized through the EU Education for Competitiveness Operational Programme. The project is funded by European Social Fund and the Czech State Budget. S.X. was supported by the State Key Program of National Natural Science of China (31230014) and the National Natural Science Foundation of China (40901019, 31000203 and 31000178). R.W.B. was sup ported by funding from the Scottish Government Rural and Environment Science and Analytical Services Division (RESAS). We thank Claire Mézière and Katja Schiffers for their help on previous versions. We would also like to thank O. Wildi, the associate editor, and two anonymous reviewers for valuable comments on earlier versions of the manuscript.

\section{References}

Adler, P.B., Seabloom, E.W., Borer, E.T., Hillebrand, H., Hautier, Y., Hector, A., Harpole, W.S., O' Halloran, L.R., Grace, J.B., Anderson, T.M., Bakker, J.D., Biederman, L.A., Brown, C.S., Buckley, Y.M., Calabrese, L.B., Chu, C. J., Cleland, E.E., Col lins, S.L., Cottingham, K.L., Crawley, M.J., Damschen, E.I., Davies, K.F., DeCrappeo, N.M., Fay, P.A., Firn, J., Frater, P., Gasarch, E.I., Gruner, D.S., Hagenah, N., Hille Lambers Ris, J., Humphries, H., Jin, V.L., Kay, A.D., Kirkman, K.P., Klein, J.A., Knops, J.M.H., La Pierre, K.J., Lambrinos, J.G., Li Mac Dougall, A.S.W., McCulley, R.L., Melbourne, B.A., Mitchell, C.E., Moore, J.L., Morgan, J.W., Mortensen, B., Orrock, J.L., Prober, S.M., Pyke, D.A., Risch, A.C., Schuetz, M., Smith, M.D., Stevens, C.J., Sullivan, L.L., Wang, G., Wragg, P.D., Wright, J.P. \& Yang, L.H. 2011. Productivity is a poor predic tor of plant species richness. Science 333: 17501753.

Al Mufti, M.M., Sydes, C.L., Furness, S.B., Grime, J.P. \& Band, S.R. 1977. A quantitative analysis of shoot phenology and dominance in herbaceous vegetation. Journal of Ecology 65: 759791.

Anthelme, F. \& Michalet, R. 2009. Grass to tree facilitation in an arid grazed environment (Air Mountains, Sahara). Basic and Applied Ecology 10: 437446.

Anthelme, F., Michalet, R. \& Saadou, M. 2007. Positive associa tions involving the tussock grass Panicum turgidum Forssk. in the Aur Tenere Natural reserve, Niger. Journal of Arid Envi ronments 68: 348362 .

Armas, C., Ramón, O. \& Pugnaire, F.I. 2004. Measuring plant interactions: a new comparative index. Ecology 85: 2682 2686.

Bertness, M.D. \& Callaway, R. 1994. Positive interactions in communities. Trends in Ecology $\theta$ Evolution 9: 191193.

Brooker, R.W. \& Callaghan, T.V. 1998. The balance between positive and negative plant interactions and relationship to environmental gradients: a model. Oıkos 81: 196201.

Brooker, R.W., Scott, D., Palmer, S.C.F. \& Swaine, E. 2006. Tran sient facilitative effects of heather on Scots pine along a graz ing disturbance gradient in Scottish moorland. Journal of Ecology 94: 637645.

Brooker, R.W., Travis, J.M.J., Clark, E.J. \& Dytham, C. 2007. Modelling species range shifts in a changing climate: the impact of biotic interactions, dispersal distance and the rate of climate change. Journal of Theoretical Biology 245: 5965. 
Brooker, R.W., Maestre, F., Callaway, R.M., Lortie, L., Cavieres, L.A., Kunstler, G., Liancourt, P., Tielborger, K., Travis, J.M.J., Anthelme, F., Armas, C., Coll, L., Corcket, E., Del zon, S., Forey, E., Kikvidze, Z., Olofsson, J., Pugnaire, F., Quiroz, C.L., Saccone, P., Schiffers, K., Seifan, M., Touzard, B. \& Michalet, R. 2008. Facilitation in plant communities: the past, the present and the future. Journal of Ecology 96: 1824 .

Bruno, J.F., Stachowicz, J.J. \& Bertness, M.D. 2003. Inclusion of facilitation in to ecological theory. Trends in Ecology $\theta$ Evolu tion 18: 119125 .

Bullieri, F., Cristaudo, C., Alestra, T. \& Benedetti Cecchi, L. 2011. Crossing gradients of consumer pressure and physical stress on shallow rocky reefs: a test of the stress gradient hypothesis. Journal of Ecology 99: 335344.

Chu, C.J., Maestre, F.T., Xiao, S., Weiner, J., Wang, Y.S., Duang, Z.H. \& Wang, G. 2008. Balance between facilitation and resource competition determines biomass density relation ships in plant populations. Ecology Letters 11: 11891197.

Dutoit, T. \& Alard, D. 1995. Permanent seed banks in chalk grassland under various management regimes: their role in the restoration of species rich plant communities. Biodiversity and Conservation 4: 939950.

Eskelinen, A. 2008. Herbivore and neighbour effects on tundra plants depend on species identity, nutrient availability and local environmental conditions. Journal of Ecology 96: 155 165.

Fridley, J.D., Grime, J.P., Huston, M.A., Pierce, S., Smart, S.M., Thompson, K., Borger, L., Brooker, R.W., Cerabolini, B.E.L., Gross, N., Liancourt, P., Michalet, R. \& Le Bagousse Pinguet, Y. 2012. Comment on "Productivity is a poor predictor of plant species richness". Science 335: 1441.

Grime, J.P. 1973. Competitive exclusion in herbaceous vegeta tion. Nature 242: 344347.

Grime, J.P. 1974. Vegetation classification by reference to strate gies. Nature 250: 2631 .

Grimm, V., Berger, U., Bastiansen, F., Eliassen, S., Ginot, V., Giske, J., Goss Custard, J., Grand, T., Heinz, S.K., Huse, G., Huth, A., Jepsen, J.U., Jørgensen, C., Mooij, W.M., Muller, B., Pe'er, G., Piou, C., Railsback, S.F., Robbins, A.M., Rob bins, M.M., Rossmanith, E., Ruger, N., Strand, E., Souissi, S., Stillman, R.A., Vabø, R., Visser, U. \& DeAnglis, D.L. 2006. A standard protocol for describing individual based and agent based models. Ecological Modelling 198: 115126.

Gross, N., Kunstler, G., Liancourt, P., de Bello, F., Suding, K.N. \& Lavorel, S. 2009. Linking individual response to biotic inter actions with community structure: a trait based framework. Functional Ecology 23: 11671178.

Gross, N., Liancourt, P., Choler, P., Suding, K.N. \& Lavorel, S. 2010. Strain and vegetation effects on local limiting resources explain the outcomes of biotic interactions. Perspec tive in Plant Ecology, Evolution and Systematics 12: 949

Hacker, S.D. \& Gaines, S.D. 1997. Some implications of direct positive interactions for community species diversity. Ecology 78: 19902003.
Hastwell, G.T. \& Facelli, J.M. 2003. Differing effects of shade induced facilitation on growth and survival during the estab lishment of a chenopod shrub. Journal of Ecology 91: 941950.

Holmgren, M., Scheffer, M., Ezcurra, E., Gutierrez, J.R. \& Moh ren, G.M.J. 2001. El Nino effects on the dynamics of terres trial ecosystems. Trends in Ecology e Evolution 16: 8994.

Homgren, M. \& Scheffer, M. 2010. Strong facilitation in mild environments: the stress gradient hypothesis revisited. Jour nal of Ecology 98: 12691275.

Huston, M. 1979. A general hypothesis of species diversity. The American Naturalist 113: 81101.

Huston, M. 1994. Biological diversity: the coexistence of species on changing landscapes. Cambridge University Press, Cambridge, UK.

Ifti, M., Killingback, T. \& Doebeli, M. 2004. Effects of neighbour hood size and connectivity on the spatial Continuous Pris oner's Dilemma. Journal of Theoretical Biology 231: 97106.

Kéfi, S., Rietkerk, M., Alados, C.L., Pueyo, Y., Papanastasis, V.P., ElAich, A. \& de Reiter, P.C. 2007. Spatial vegetation patterns and imminent desertification in Mediterranean arid ecosys tems. Nature 449: 213217.

Le Bagousse Pinguet, Y., Gross, E.M. \& Straile, D. 2012a. Release from competition and protection determine the outcome of plant interactions along a grazing gradient. Oikos 121:95 101.

Le Bagousse Pinguet, Y., Liancourt, P., Gross, N. \& Straile, D. 2012b. Indirect facilitation promotes macrophyte survival and growth in freshwater ecosystems threatened by eutro phication. Journal of Ecology 100: 530538.

Le Roux, P.C. \& McGeoch, M.A. 2010. Interaction intensity and importance along two stress gradients: adding shape to the stress gradient hypothesis. Oecologia 162: 733745.

Liancourt, P., Callaway, R.M. \& Michalet, R. 2005. Stress toler ance and competitive response ability determine the out come of biotic interactions. Ecology 86: 16111618.

Liancourt, P., Choler, P., Gross, N., Thibert Plante, X. \& Tielbor ger, K. 2012. How facilitation may interfere with ecological speciation. International Journal of Ecology 2012: 725487. Doi: $10.1155 / 2012 / 725487$.

Maalouf, J. P., Le Bagousse Pinguet, Y., Marchand, L., Bâche lier, E., Touzard, B. \& Michalet, R. 2012. Integrating climate change into calcareous grassland management. Journal of Applied Ecology 49: 795802.

Maestre, F.T. \& Cortina, J. 2004. Do positive interactions increase with abiotic stress? A test from a semi arid steppe. Proceedings of the Royal Society of London Series B, Biological Sci ences 271: 331333.

Maestre, F.T., Valladares, F. \& Reynolds, J.F. 2005. Is the change of plant plant interactions with abiotic stress predictable? A meta analysis of field results in arid environments. Journal of Ecology 93: 748757.

Malkinson, D. \& Tielborger, K. 2010. What does the stress gradi ent hypothesis predict? Resolving the discrepancies. Oikos 119: 15461552.

Menge, B.A. \& Sutherland, J.P. 1987. Community regulation: variation in disturbance and predation in relation to envi 
ronmental stress and recruitment. The American Naturalist 130: 730757.

Michalet, R., Gandoy, C., Joud, D., Pages, J.P. \& Choler, P. 2002 Plant community composition and biomass on calcareous and siliceous substrates in the northern French Alps: com parative effects of soil chemistry and water status. Arctic, Ant arctic and Alpine Research 34: 102113.

Michalet, R., Brooker, R.W., Cavieres, L.A., Kikvidze, Z., Lortie, C.J., Pugnaire, F.I., Valiente Banuet, A. \& Callaway, R.M. 2006. Do biotic interactions shape both sides of the humped back model of species richness in plant communi ties? Ecology Letters 9: 767773.

Michalet, R., Xiao, S., Touzard, B., Smith, D.S., Cavieres, L., Call away, R.M. \& Whittham, T.G. 2011. Phenotypic variations in nurse traits and community feedbacks define an alpine community. Ecology Letters 14: 433443.

Scheffer, M. \& Carpenter, S. 2003. Catastrophic regime shift in ecosystems: linking theory to observation. Trends in Ecology $\theta$ Evolution 18: 648656.

Smit, C., Vandenberghe, C., den Ouden, J. \& Muller Scharer, H. 2007. Nurse plants, tree saplings and grazing pressure: changes in facilitation along a biotic environmental gradient. Oecologia 152: 265273.

Travis, J.M.J., Brooker, R.W. \& Dytham, C. 2005. The interplay of positive and negative species interactions across an envi ronmental gradient: insights from an individual based simu lation model. Biology Letters 1: 58 .

Travis, J.M.J., Brooker, R.W., Clark, E.J. \& Dytham, C. 2006. The distribution of positive and negative species interactions across environmental gradients on a dual lattice model. Jour nal of Theoretical Biology 241: 896902.
Veblen, K.E. 2008. Season and herbivore dependent competi tion and facilitation in a semiarid savanna. Ecology 89: 1532 1540 .

Xiao, S., Michalet, R., Wang, G. \& Chen, S.Y. 2009. The interplay between positive and negative interactions shapes the "community biomass species richness" relationship. Oikos 118: 13431348 .

Xiao, S., Zobel, M., Szava Kovats, R. \& Partel, M. 2010. The effects of species pool, dispersal and competition on the diversity productivity relationship. Global Ecology and Bioge ography 19: 343351.

Yamamura, N., Higashi, M., Behera, N. \& Wakano, J.Y. 2004. Evolution of mutualism through spatial effects. Journal of Theoretical Biology 226: 421428 .

Zavaleta, E.S., Shaw, M.R., Chiariello, N.R., Mooney, H.A. \& Field, C.B. 2003. Additive effects of simulated climate changes, elevated $\mathrm{CO}_{2}$, and nitrogen deposition on grassland diversity. Proceedings of the National Academy of Sciences of the United States of America 100: 76507654. 